\title{
Botulismo Alimentar: Uma Doença Esquecida
}

\section{Foodbourne Botulism: A Forgotten Disease}

Paula NEVES $\triangle^{1}$, Jorcélio VICENTE ${ }^{1}$, Heidy CABRERA $^{1}$, lurie PANTAZI ${ }^{1}$

Acta Med Port 2018 Nov;31(11):691-693 - https://doi.org/10.20344/amp.9453

RESUMO

O botulismo é uma doença grave causada pela exposição a toxina botulínica. Manifesta-se por paralisia flácida, simétrica e em padrão descendente que afeta nervos cranianos e periféricos. Dada a frequente necessidade de ventilação mecânica invasiva, estes doentes devem ser abordados em ambiente de cuidados intensivos. O tratamento com soro anti-toxina botulínica é o único eficaz. Os autores apresentam o caso de uma doente de 64 anos, com quadro de vómitos e vertigem, com evolução para diplopia, disfagia e parésia muscular flácida, simétrica e descendente, com instalação após ingestão de conserva alimentar de fabrico caseiro. Do estudo etiológico salienta-se eletroneuromiograma com lesão pré sináptica compatível com hipótese de botulismo. Melhoria progressiva dos défices após administração de soro anti-toxina botulínica. Faz-se uma breve revisão teórica de uma patologia grave, potencialmente fatal e pouco frequente no nosso país.

Palavras-chave: Antitoxina Botulínica; Botulismo; Clostridium botulinum; Doenças Transmitidas por Alimentos

\section{ABSTRACT}

Botulism is a serious illness caused by exposure to botulinum toxin. It is manifested by flaccid, paralysis, symmetric and in descending pattern affecting cranial and peripheral nerves. Given the frequent need for invasive mechanical ventilation, these patients should be approached in an intensive care setting. Treatment with anti-botulinum toxin is the only effective treatment. The authors present the case of a 64-year-old patient, with vomiting and vertigo, evolution to diplopia, dysphagia and flaccid, muscle paralysis, installation after ingestion of canning homemade. From the etiologica, we highlight the electroneuromyogram study with a pre-synaptic lesion compatible with the botulism hypothesis. Progressive improvement of the deficits after administration of anti-botulinum toxin. A brief theoretical review is made of a serious, potentially fatal and infrequent pathology in our country.

Keywords: Botulinum Antitoxin; Botulism; Clostridium botulinum; Foodborne Diseases

\section{INTRODUÇÃO}

Botulismo é uma doença grave, de início súbito, causada pela exposição a toxina botulínica. A espécie Clostridium botulinum é um agente ubiquitário, presente no solo e em meios aquáticos. Produz sete toxinas designadas pelas letras $\mathrm{A}-\mathrm{H}$, sendo as mais patogéneas as toxinas tipo $A, B$, $E$ e mais raramente $F^{1,2}$ Subdivide-se em quatro grandes síndromes: botulismo alimentar, botulismo associado a feridas, botulismo infantil e toxémia intestinal do adulto. ${ }^{1}$

Salienta-se que o Clostridium botulinum e a sua toxina são considerados pelo Centers for Disease Control and Prevention de Atlanta um importante agente biológico potencialmente usado em bioterrorismo. De acordo com este organismo, este microorganismo é considerado um agente categoria $A$, ou seja, agente que representa risco elevado para a segurança nacional dado poder ser facilmente disseminado, causar elevada taxa de mortalidade, pânico na sociedade ou necessitar de medidas especiais de controlo de Saúde Pública para os quais o sistema pode não estar preparado, estando inclusive documentadas acções criminosas utilizando esta toxina em bases militares japonesas. ${ }^{3,4}$

De todas as formas conhecidas, o botulismo alimentar é a forma mais frequente estando associada à ingestão de alimentos contendo toxina botulínica, sendo a toxina do tipo $B$ a mais frequentemente identificada nos países europeus.

Após absorção a toxina é transportada via hematogénia até às terminações nervosas, sem atingimento do sistema nervoso central. As toxinas atuam nas junções neuromusculares ligando-se à membrana nervosa, inibindo a libertação de acetilcolina e provocando paralisia motora sem interferência com a função sensorial ou nível de consciência. Os nervos mais afetados são os periféricos. ${ }^{5,6}$

O quadro clínico caracteriza-se por paralisia flácida simétrica e descendente que afeta os pares cranianos e os nervos autonómicos. Inicia-se nos nervos cranianos (os quais estão invariavelmente envolvidos) e progride para os músculos respiratórios, membros superiores, e finalmente membros inferiores conduzindo a falência respiratória e morte. , $^{1,5-8}$

Sendo esta uma patologia rara, o diagnóstico das formas esporádicas é frequentemente negligenciado, sendo sugerido pela clínica neurológica típica. Na maioria dos casos há evolução para falência respiratória com necessidade de ventilação mecânica invasiva (VMI) e o tratamento com anti-toxina botulínica é o único tratamento específico.

\section{CASO CLÍNICO}

Doente do sexo feminino, 64 anos, com história pessoal de hipertensão arterial e dislipidémia. Recorreu pela primeira vez ao Serviço de Urgência (SU) por quadro de vómitos alimentares e vertigens medicada sintomaticamente com beta-histina. Regressa três dias depois por manutenção

\footnotetext{
1. Serviço de Medicina Interna. Hospital Sousa Martins. Guarda. Portugal.

$\triangle$ Autor correspondente: Paula Neves. paulacatarinaneves@gmail.com

Recebido: 18 de julho de 2017 - Aceite: 16 de abril de 2018 | Copyright $\odot$ Ordem dos Médicos 2018
} 
das queixas prévias associadas a quadro de visão turva e disfagia para sólidos e líquidos. Proposto internamento que a doente recusou. Regressa novamente ao SU quatro dias depois por agravamento das queixas de disfagia, associadas a astenia e ataxia da marcha. Negou outras queixas gastrointestinais, cefaleias, febre ou sintomatologia semeIhante em contactos próximos.

À admissão nesta última vinda ao SU encontrava-se hemodinamicamente estável. Do exame neurológico salienta-se doente vígil e orientada no tempo, espaço, alo e auto-psiquicamente, apresentando midríase bilateral com ligeira ptose bilateral e ataxia da marcha. Movimentos oculares conservados, sem nistagmo, parésia facial, défices motores ou sensitivos. Sem sinais meníngeos ou outras alterações ao exame físico. A avaliação analítica e a tomografia computorizada de crânio realizadas não revelaram alterações. Foi também submetida a punção lombar que excluiu processo infeccioso associado.

É então internada na Unidade de Acidentes Vasculares Cerebrais (AVC) com a hipótese diagnóstica de AVC do tronco.

Durante o internamento constatou-se instalação de diplopia e obstipação, mantendo a sintomatologia inicial.

Realizou ressonância magnética de crânio que não mostrou patologia aguda. Ao sexto dia de internamento apresentava hipotonia generalizada, com quadro de hipotensão e insuficiência respiratória grave que motivaram transferência para a Unidade de Cuidados Intensivos (UCI).

Neste momento é feita revisão da história clínica, com inquérito epidemiológico à doente que residia sozinha e aos contactos próximos (irmã, sobrinha e vizinha), apurando-se ingestão de omelete confecionada com conserva de cogumelos caseiros congelados cerca de uma semana antes do presente internamento. É colocada a hipótese de botulismo sendo-Ihe administrado soro anti-toxina botulínica (com atividade contra as toxinas $A, B$ e E) com melhoria progressiva da sintomatologia descrita. Não houve necessidade de VMI durante o internamento na $\mathrm{UCI}$.

Do restante estudo etiológico realizado realça-se eletroneuromiograma e potenciais evocados dos membros superiores que evidenciaram lesão pré sináptica da junção neuromuscular compatível com hipótese de botulismo. A pesquisa de toxina botulínica (A, B, E e F por inoculação em ratinho) no sangue e nas fezes foi negativa. Não foi possível realizar análise microbiológica do alimento suspeito dado o mesmo já não se encontrar disponível.

Alta após 26 dias de internamento mantendo ainda ataxia da marcha e disfagia a líquidos. Manteve programa de reabilitação em ambulatório com resolução completa dos sintomas três meses após o internamento.

\section{DISCUSSÃO E CONCLUSÃO}

Botulismo alimentar é uma doença rara na Europa e em Portugal (60 casos registados na União Europeia, dos quais oito em Portugal em 2015), ${ }^{9,10}$ resultando da ingestão de alimentos contaminados com toxina botulínica (de acordo com dados nacionais, os alimentos mais frequentemente implicados são o presunto e a alheira). ${ }^{9}$ No entanto, o regresso a tradições antigas tem levado ao aumento de casos registados, revelando-se as conservas caseiras e o fumeiro a principal fonte de intoxicação alimentar. ${ }^{1,5,8,10}$ Habitualmente não há alteração das características dos alimentos contaminados. ${ }^{5}$

$\mathrm{Na}$ fase inicial da doença, os doentes referem boca seca, diplopia e ptose, seguidos de disfonia, disartria e disfagia. Os sintomas autonómicos também são frequentes manifestando-se por edema da mucosa e hipotensão. Posteriormente há progressão para paralisia dos músculos periféricos em padrão descendente. Geralmente a morte ocorre por obstrução respiratória devida à paresia dos músculos faríngeos ou por volume corrente inadequado devido à paresia dos músculos respiratórios. ${ }^{1,5-7}$

Os sintomas têm início 18 - 36 horas após a exposição e os sintomas gastrointestinais precedem os neurológicos. ${ }^{7}$

O diagnóstico é sugerido pelas manifestações neurológicas típicas, e estabelecido pela detecção de toxina. ${ }^{1,7,11}$ Se realizado por um médico experiente, o eletroneuromiograma é um importante auxílio no diagnóstico podendo identificar sinais de bloqueio da junção neuromuscular, com condução axonal normal e estimulação potenciadora rápida e repetitiva. ${ }^{1}$ A punção lombar não apresenta alterações. ${ }^{1}$

O diagnóstico diferencial inclui a síndrome de Guillain-Barré, miastenia gravis e acidente vascular cerebral (particularmente da basilar). ${ }^{1} \mathrm{O}$ tratamento com soro anti-toxina botulínica é o único tratamento específico, permitindo evitar a progressão da paralisia, diminuir a duração da mesma e a dependência de VMI e deve ser administrado o mais precocemente possível. ${ }^{1}$ Uma única dose é suficiente na maioria dos casos. ${ }^{7}$

Preconiza-se que estes doentes sejam internados em $\mathrm{UCl}$ com monitorização apertada. ${ }^{1}$

A paralisia tem resolução ao fim de várias semanas a meses sob programas intensivos de reabilitação. ${ }^{1}$

Apresentamos o caso de uma doente com diagnóstico provável de botulismo. Apesar da pesquisa de toxina botulínica ter sido negativa, a história clínica, a sintomatologia da doente, a boa resposta ao tratamento com soro anti-toxina botulínica e a lesão pré sináptica evidenciada no electroneuromiograma corroboram esta hipótese de diagnóstico. Salienta-se que, apesar de introdução tardia de soro anti-toxina botulínica, a doente teve evolução favorável após a administração do mesmo. A possibilidade de realizar análise microbiológica do alimento suspeito teria trazido um importante contributo no diagnóstico definitivo desta patologia, mas tal não foi possível. Com este caso pretendemos salientar a importância da suspeição clínica em fase precoce de uma patologia potencialmente fatal, com manifestações típicas e bem caracterizadas, cujo diagnóstico é muitas vezes negligenciado dada a baixa incidência da mesma no nosso país. Na opinião dos autores, apesar do botulismo ser uma doença de declaração obrigatória, na maioria das vezes os casos suspeitos ou confirmados não são notificados, o que faz com que a doença seja ainda 
menos conhecida do que seria de esperar.

Salientamos ainda o facto do Clostridium ser um microorganismo ubiquitário, com diversas espécies potencialmente causadoras de doença grave, particularmente pela produção de toxina como é o caso de Clostridium botulinum e Clostridium tetani - este último, um agente com elevada capacidade de sobrevivência e causador de doença rara mas quase sempre invariavelmente fatal.

\section{AGRADECIMENTOS}

Os autores agradecem a Luís Paulo Trindade, da Unidade de Cuidados Intensivos Polivalente do Hospital Sousa Martins, na Guarda.

\section{PROTEÇÃO DE PESSOAS E ANIMAIS}

Os autores declaram que os procedimentos seguidos estavam de acordo com os regulamentos estabelecidos pelos responsáveis da Comissão de Investigação Clínica

\section{REFERÊNCIAS}

1. Sobel J. Botulism. Food safety. Clin Infect Dis. 2005;41:1167-73.

2. Espelund M, Klaveness D. Botulism outbreaks in natural environments - an uptodate. Front Microbiol. 2014;5:287

3. Emergency preparedness and response. Update August 17. 2017. [consultado em 2018 jun 12]. Disponível em: http://emergency.cdc.gov/ bioterrorism/factsheets.asp.

4. Desta S, Melaku M, Abdela N. Botulinum toxin and its biological significance: a review. Austin J Vet Sci Anim Husb. 2016;3:id1021.

5. Cereser N, Costa M, Júnior O, Silva D, Sperotto V. Botulismo de origem alimentar. Ciência Rural. Santa Maria. 2008;38:280-7.

6. Carrillo-Marquez M. Botulism. Pediatr Rev. 2016;37:183-92.

7. World Health Organization. International Programme on Chemical e Ética e de acordo com a Declaração de Helsínquia da Associação Médica Mundial.

\section{CONFIDENCIALIDADE DOS DADOS}

Os autores declaram ter seguido os protocolos do seu centro de trabalho acerca da publicação de dados.

\section{CONSENTIMENTO DO DOENTE}

Obtido.

\section{CONFLITOS DE INTERESSE}

Os autores declaram não terem qualquer conflito de interesse relativamente ao presente artigo.

\section{FONTES DE FINANCIAMENTO}

Não existiram subsídios ou bolsas que tenham contribuído para a realização do trabalho.

Safety Poisons Information Monograph 858 Bacteria. Genova: WHO; 2002.

8. The European Union summary report on trends and sources of zoonoses, zoonotic agents and food-borne outbreaks in 2015. EFSA J. 2016;14:4634.

9. Viegas S, Cunha I, Correia C, Coelho A, Maia C, Pena C, et al. Investigação laboratorial de surtos de toxinfecções alimentares, 2015. Lisboa: Instituto Nacional de Saúde Doutor Ricardo Jorge; 2015.

10. Brola W, Fudala M, Gacek S, Gruenpeter P. Food-borne botulism: still actual topic. BMJ Case Rep. 2013;2013. pii: bcr2012007799.

11. Almasqué I. Relembrar o botulismo. Rev Med Int. 1998;1:60-2. 